\title{
A STUDY OF THE DEVELOPMENT OF TAIWAN MARITIME CASUALTY DATABASE SYSTEM
}

\author{
Solomon Y.H Chen \\ of Maritime Business, Australian Maritime College, solomon@safetysea.org \\ Kevin K.M Su \\ System Engineer, Seafarers Training Centre, National Kaohsiung Maritime University
}

Associate Professor, Department of Merchant Marine, National Taiwan Ocean University Visiting Scholar, Department

Follow this and additional works at: https://jmstt.ntou.edu.tw/journal

Part of the Business Commons

\section{Recommended Citation}

Chen, Solomon Y.H and Su, Kevin K.M (2005) "A STUDY OF THE DEVELOPMENT OF TAIWAN MARITIME CASUALTY DATABASE SYSTEM," Journal of Marine Science and Technology. Vol. 13: Iss. 3, Article 6.

DOI: $10.51400 / 2709-6998.2127$

Available at: https://jmstt.ntou.edu.tw/journal/vol13/iss3/6

This Research Article is brought to you for free and open access by Journal of Marine Science and Technology. It has been accepted for inclusion in Journal of Marine Science and Technology by an authorized editor of Journal of Marine Science and Technology. 


\title{
A STUDY OF THE DEVELOPMENT OF TAIWAN MARITIME CASUALTY DATABASE SYSTEM
}

\author{
Solomon Y.H. Chen* and Kevin K.M. Su**
}

Key words: Taiwan Martime Casualty Database System (TMCDS), marine casualties and incidents.

\begin{abstract}
With the aim of creating a comprehensive maritime casualty database which will facilitate an efficient maritime safety management system for Taiwanese government, this study designs and establishes a Taiwan Maritime Casualty Database System (TMCDS). Following the guidelines from the Code for the Investigation of Marine Casualties and Incidents of the IMO and also through a comparative study resulting from the different maritime investigation authorities, this study structures a comprehensive component of such a database. Furthermore, based on the Structured Query Language (SQL) Command and adopting the technology of Active Server Pages (ASP) and Active Data Object (ADO), a three-tier maritime casualty database structure is created through Web server for the convenience of database management to be used by either client or server interactively.
\end{abstract}

\section{INTRODUCTION}

A proper investigation and analysis of maritime casualties and incidents can lead to a greater awareness of casualty causation and provide useful remedial measures. Taking into account the rights and obligations of coastal and flag states, under the provisions of articles 2 and 94 of the United Nations Convention on the Law of the Sea (UNCLOS), a flag State shall cause an inquiry into certain casualties or incidents of navigation which might pose a risk to life or to the environment, involve the coastal state search and rescue (SAR) authorities, or otherwise affect the coastal State. Also, under relevant IMO conventions, such as SOLAS regulation I/21 and MARPOL 73/78 articles 8 and 12, each Administration undertakes to conduct an investigation into any casualty occurring to ships under its flag subject to those conventions and to supply the IMO with

Paper Submitted 10/22/04, Accepted 04/12/05. Author for Correspondence: Solomon Chen. E-mail: solomon@safetysea.org.

*Associate Professor, Department of Merchant Marine, National Taiwan Ocean University Visiting Scholar, Department of Maritime Business, Australian Maritime College.

**System Engineer, Seafarers Training Centre, National Kaohsiung Maritime University. pertinent information concerning the findings of such investigations. The Load Lines Convention article 23 also requires the investigation of casualties.

In compliance with the international regulations mentioned in the above, many countries establish a specific national authority to carry out maritime casualty investigations. Some examples are Australian Transport Safety Bureau (ATSB), British Marine Accident Investigation Branch (MAIB), Japanese Marine Accidents Inquiry Agency (MAIA), New Zealand Transport Accident Investigation Commission (TAIC), Swedish Board of Accident Investigation, Transportation Safety Board of Canada (TSB), and US Coastguard Office of Investigation and Analysis and US National Transportation Safety Board (NTSB). In addition, international organisations such as IMO Maritime Safety Committee, European Maritime Safety Agency, Marine Accident Investigators International Forum (MAIIF), and International Transportation Safety Association have devoted themselves towards safer shipping and cleaner oceans.

Despite the best endeavours of the international organisations and flag states, casualties and incidents resulting in loss of life, loss of ships and pollution of the marine environment continue to occur. In fact, to learn from the casualty itself is one of the most effective measures to reduce the risk of occurrence of the next casualty. Therefore, the analysis of causalities through different methodologies and techniques, such as incident modelling, causal analysis, event-based approaches, check-list approaches, mathematical models of causation, and comparisons, to identify and eliminate the regulatory, managerial, hardware, software, human or organisational failures or factors leading to a casualty is important. However, these techniques can only be successfully employed on the basis of an accurate, detailed, and accessible maritime casualty database management system.

This study, therefore, aims to structure a comprehensive three-tier maritime casualty database system through Web server. The system design follows guidelines from the Code for the Investigation of Marine Casualties and Incidents of the IMO and also through a 
comparative study resulting from the different maritime investigation authorities. Moreover, this study is to create a prototype of TMCDS, which will be a useful tool to facilitate an efficient maritime safety management for Taiwanese maritime safety authorities.

\section{EXISTING MARITIME CASUALTIES INVESTIGATION IN TAIWAN}

The island of Taiwan straddles the Tropic of Cancer, about 200 kilometres off the eastern shore of the Chinese mainland. It is strategically located in the East China Sea, between Japan and Korea to the North, and Hong Kong and the Philippines to the South. With a land area of 36,000 square kilometres, it is comparable in size to the Netherlands.

Maritime transport is vital to Taiwan's trade-oriented economy. By weight, almost $99.59 \%$ of imports and exports in Taiwan were transported by sea [2]. According to the International Trade Statistics 2003 by WTO, Taiwan was the world's 14th largest exporter and 16 th largest importer. In addition to the Taiwanese domestic fleet, there are well over two hundred ships with foreign flags transiting Taiwanese waters daily from the Pacific Ocean to the South China Sea. Besides, Taiwan has in excess of twenty-seven thousand registered fishing vessels ranging from very small nonpowered crafts to very large ships, $81 \%$ of the vessels are less than fifty tonnes in displacement. These large amounts of not-well equipped fishing vessels and small general cargo ships crossing the Formosa Strait between
Taiwan and China are not only increasing the risk to the mariners navigating in this high-density sea traffic area but also to the marine environment and properties [3].

Taiwan's maritime casualty database on the one hand is governed by different administrative authorities. Harbour bureausauthorities are responsible for all the reported maritime casualties that occur in their port jurisdiction region, and report to the Ministry of Transport and Communication (MOTC). Record of casualties from fishing vessels on the other hand are kept by the Fisheries Agency of the Council of Agriculture under Executive Yuan (FA). In the meantimes, the Taiwan Coast Guard Administration keeps data of all Search and Rescue cases. Finally, the Environment Protection Agency keeps records of marine pollutions.

The recording of maritime casualties' data by various government agencies indicates that the fatality and missing rates are fairly high. According to the information collected from harbour bureaus, an average 290 cases of maritime casualties occur annually in the SAR responsibility area of Taiwan. As far as fishing vessels are concerned, there are about 500 cases each year. Nevertheless it has been pointed out that there are missing figures regarding the fatalities arising from fishing vessels casualties because of the inaccuracy in reporting the actual number of crew on board. Consequently, it is estimated that the actual number of lives lost might be somewhat higher than that provided in the official statistics (Table 1).

Comparing with those countries that have a national authority to carry out maritime casualty

Table 1. Statistics of maritime casualties (1.1.1992 31.12.2002)

Data collected from harbour bureaus, Ministry of Transport and Communication (MOTC)*

\begin{tabular}{cccccc}
\hline Year & $\begin{array}{c}\text { Number } \\
\text { of } \\
\text { casualties }\end{array}$ & $\begin{array}{c}\text { Vessel } \\
\text { damage }\end{array}$ & $\begin{array}{c}\text { Vessel } \\
\text { sunk }\end{array}$ & Injured & $\begin{array}{c}\text { Death/ } \\
\text { missing }\end{array}$ \\
\hline 1992 & 372 & 148 & 63 & 23 & 50 \\
1993 & 299 & 137 & 41 & 7 & 54 \\
1994 & 280 & 153 & 43 & 13 & 32 \\
1995 & 214 & 95 & 39 & 4 & 30 \\
1996 & 301 & 142 & 35 & 8 & 75 \\
1997 & 306 & 143 & 19 & 6 & 15 \\
1998 & 295 & 120 & 40 & 7 & 42 \\
1999 & 315 & 133 & 68 & 13 & 44 \\
2000 & 287 & 142 & 64 & 10 & 112 \\
2001 & 276 & 105 & 44 & 50 & 36 \\
2002 & 254 & 81 & 41 & 13 & 29 \\
2003 & 276 & 126 & 44 & 15 & 47 \\
Total & 3475 & 1525 & 541 & 169 & 566 \\
Average & 289.58 & 127.08 & 45.08 & 14.08 & 47.17 \\
\hline
\end{tabular}

* Definition of casualties by MOTC includes: collision, grounding/stranding, fire, explosion, oil spill, capsized, machinery failure, extraordinary and others.
Data collected from Fisheries Agency (FA), Council of Agriculture, Executive Yuan**

\begin{tabular}{ccccccc}
\hline Year & $\begin{array}{c}\text { Number } \\
\text { of } \\
\text { casualties }\end{array}$ & $\begin{array}{c}\text { Vessel } \\
\text { sunk or } \\
\text { missing }\end{array}$ & Death & $\begin{array}{c}\text { Serious } \\
\text { injured }\end{array}$ & Injured & Missing \\
\hline 1992 & 451 & 124 & 89 & 13 & 49 & 73 \\
1993 & 275 & 53 & 70 & 12 & 19 & 38 \\
1994 & 433 & 49 & 69 & 11 & 8 & 43 \\
1995 & 378 & 39 & 65 & 12 & 9 & 40 \\
1996 & 1032 & 155 & 73 & 10 & 19 & 65 \\
1997 & 441 & 42 & 46 & 12 & 30 & 21 \\
1998 & 552 & 49 & 59 & 12 & 39 & 25 \\
1999 & 527 & 96 & 62 & 6 & 77 & 18 \\
2000 & 519 & 96 & 68 & 16 & 38 & 14 \\
2001 & 556 & 109 & 58 & 11 & 92 & 20 \\
2002 & 442 & 70 & 59 & 8 & 51 & 18 \\
2003 & 383 & 49 & 45 & 10 & 48 & 21 \\
Total & 5989 & 931 & 763 & 133 & 479 & 396 \\
Average & 499.08 & 77.58 & 63.58 & 11.08 & 39.92 & 33.00 \\
\hline
\end{tabular}

** Definition of casualties by FA includes: weather damage, engine breakdown, collision, flooding/leaking, grounding/stranding, fire, propeller twisted and others. 
investigation, the Taiwan's maritime safety afairs are governed by various government authorities. As a result, none of these agencies could present a true picture of maritime casualties in Taiwan [1]. As a consequence, this leads to an inefficient and ineffective management system of the investigation of maritime casualties, which will impede the achievement in preventing or reducing the risk of occurrence of another casualty by learning from pervious casualties. Additionally, it is anticipated that in the future, once the water is open to leisure boats and various maritime activities, or the ban on direct shipping between mainland China and Taiwan be lifted, the number of maritime casualties may further increase. In view of the shortcomings of existing maritime safety management system and the consideration of the possible increase in the volume of traffic, it is necessary for the government to have a comprehensive and efficient maritime safety management system in place to achieve the goal of increasing effectiveness and working towards a seamless integration with international procedures on the maritime accident investigation.

Revealed by this study, the current data of maritime casualties kept in various agencies are mainly hardcopy only, with some in Microsoft WORD format. Furthermore, information collected from these agencies are generally less comprehensive, limited and sometimes very rough. Only very limited cases are investigated or discussed. This does not comply with IMO MSC/Circ 953 and other requirements. Hence, with the aim of establishing an efficient maritime safety management system, it is necessary for the government to integrate the data of maritime casualties from various agencies so that a comprehensive maritime casualty database can be established.

\section{STRUCTURE OF MARITIME CASUALTY DATABASE}

\section{Development environment}

With its three tier architecture, the Taiwan Maritime Casualty Database System (TMCDS) aims to create a user-friendly environment through wide, interactive, and accessible internet at http://www. safetysea.org. The client-side (user interface) system is used as browser to connect the interactive function provided by web server and Maritime Casualty Database on server-side.

TMCDS employs ActiveX Data Objects (ADO) and Active Server Pages (ASP) techniques to retrieve data from a SQL Server database. Active Server Pages (ASP) is a standard programming system for Internet applications hosted on the server-side execution environment in Microsoft Internet Information Server (IIS). APS enables users to open a compile-free application environment, in which HTML pages, scripts, and ActiveX server components can be combined to create powerful Web-based business solutions to be dynamic and interactive by embedding scripts, i.e. either VBScript or JScript, Microsoft's alternative of JavaScript. The environment of developing TMCDS are summarised in Table 2.

\section{Data Structure}

The basic database structure of TMCDS is designed on the basis of Taiwan's existing maritime casualty report forms collected from various administrative agencies, and relevant resources such as:

(1) IMO Sub-Committee on Flag State Implementation - 5th session, casualty database construction submitted by Norway, and reports submitted by Netherlands and Australia.

(2) IMO Resolution A.849 (20), Code for the Investigation of Marine Casualties and Incidents.

(3) IMO Resolution A.884 (21), Amendments to the Code for the Investigation of Marine Casualties and Incidents (Resolution A.849).

(4) IMO MSC/Circ.953, MEPC/Circ.372, Reports on Marine Casualties and Incidents, Revised harmonized reporting procedures - Reports required under SOLAS regulation I/21 and MARPOL 73/78 articles 8 and 12.

(5) Norwegian Maritime Directorate, KS-0197 E Marine Casualty Report.

(6) Guidelines and Investigators Manual, Marine Accident Investigator's International Forum.

Table 2. TMCDS environment

\begin{tabular}{ll}
\hline Front-end & Visual Studio 6.0, Mse 6.0, and Frontpage 2000 \\
\hline Database & Access 2000 \\
Web-server & Internet Information Server (IIS) 5.0 \\
Platform & MS-Windows 2000, MS-Windows NT Server 2000 \\
Tools & Microsoft Development Environment (Mse 6.0), Frontpage Server Extension, \\
& Microsoft Office 2000, WS_FTP, Microsoft Internet Explorer 6.0, Adobe Photoshop 5.0 \\
\hline
\end{tabular}


(7) Guidelines and report forms from Australian National Search and Rescue Manual (Australia), National Search and Rescue Manual and SAR Seamanship Reference Manual (Canada), National Search and Rescue Committee (USA), Search and Rescue Manual (IMO/ICAO).

According to the characteristics of each casualty, data structure are categorised into static data and dynamic data through five data types to explain casualties, namely, characters (attribute, phrase), logic, number, date, and summary.
Static data are data which will not be affected by accident and incident, such as particulars of ships (Table 3 ) and information on seafarers (Table 4).

The structure of dynamic data is created on the basis of the SHEL model to describe data with respect to the occurrence and consequences of a casualty [4]. These dynamic data include On-scene data (Table 5), Ship's factors (Table 6), Environmental factors (Table 7), Human factors (Table 8), and Consequences of the incident (Table 9).

Table 3. Static data structure-particulars of ships

\begin{tabular}{|c|c|c|c|c|c|}
\hline $\begin{array}{l}\text { Name of } \\
\text { field }\end{array}$ & Content & $\begin{array}{c}\text { Type of } \\
\text { data }\end{array}$ & $\begin{array}{l}\text { Name of } \\
\text { field }\end{array}$ & Content & $\begin{array}{c}\text { Type of } \\
\text { data }\end{array}$ \\
\hline Imo_num & IMO number & Character & Pre_class & Previous class society & Character \\
\hline Nat_num & National reg number & Character & Keel_laid & Keel laid (yyyy/mm/dd) & Date \\
\hline Ship_name & Name of ship & Character & Deli_date & Delivery date (yyyy/mm/dd) & Date \\
\hline Flag_state & Flag state & Character & Dwt & DWT (tons) & Number \\
\hline Ship_type & Type of ship & Character & Hull_mater & Hull material & Character \\
\hline Grt & GRT (tons) & Number & Hull_constru & Hull construction & Character \\
\hline Length & Length overall & Number & Build_yard & Building yard & Character \\
\hline Width & Width of ship & Number & Hull_num & Hull number & Character \\
\hline Ship_class & Classification ship & Character & Crew_num & Number of crew & Number \\
\hline Shipowner & Registered ship owner & Character & Passen_num & Number of passengers & Number \\
\hline Manager & Ship manager & Character & Data_source & Source of data & Character \\
\hline Pre_name & Previous names & Character & Writer & Import & Character \\
\hline Pre_flag & Previous flag & Character & Write_date & Date to import & Character \\
\hline
\end{tabular}

Table 4. Static data structure- information on seafarers

\begin{tabular}{llllll}
\hline $\begin{array}{c}\text { Name of } \\
\text { field }\end{array}$ & Content & $\begin{array}{c}\text { Type of } \\
\text { data }\end{array}$ & $\begin{array}{c}\text { Name of } \\
\text { field }\end{array}$ & Content & $\begin{array}{c}\text { Type of } \\
\text { data }\end{array}$ \\
\hline Rank & Rank & Character & Tele & Telephone & Character \\
Crew_name & Crew name & Character & Serv_com & Service company & Character \\
Addre_in & Address & Character & Hold_lice & License hold & Character \\
Nation_in & Nation & Character & & & \\
\hline
\end{tabular}

Table 5. On-scene data

\begin{tabular}{|c|c|c|c|c|c|}
\hline $\begin{array}{l}\text { Name of } \\
\text { field }\end{array}$ & Content & $\begin{array}{c}\text { Type of } \\
\text { data }\end{array}$ & $\begin{array}{l}\text { Name of } \\
\text { field }\end{array}$ & Content & $\begin{array}{c}\text { Type of } \\
\text { data }\end{array}$ \\
\hline Ship_caur & Course & Number & Visib & Visibility scale & Character \\
\hline Speed & Speed (knots) & Number & Wind_scale & Beaufort scale & Character \\
\hline Wind_caur & Wind course & Character & Sea_state & State of sea & Character \\
\hline Etd & ETD: (yyyy/mm/dd): (hh:mm) & Date, time & Swell_state & Douglas swell & Character \\
\hline Eta & ETA: (yyyy/mm/dd): (hh:mm) & Date, time & Water_depth & Depth of water & Number \\
\hline Weat_conti & Weather notation & Character & & & \\
\hline
\end{tabular}


Table 6. Ship's factors

\begin{tabular}{llllll}
\hline Name of field & Content & Type of data & Name of field & Content & Type of data \\
\hline Struct_fail & Structural failure & Logic & Equi_fail & Failure equipment & Character \\
Design_fail & Failure to ship's design & Logic & Cargo_cause & Cause to cargo & Character \\
Main_fail & Failure machine & Character & Oth_ship_cause & Other cause of ship & Summary \\
\hline
\end{tabular}

Table 7. Environmental factors

\begin{tabular}{llllll}
\hline Name of field & Content & Type of data & Name of field & Content & Type of data \\
\hline Othship_unact & Other ship unsafe action & Logic & Aids_fail & Failure of aids navigation & Character \\
Busy_water & Busy water & Logic & Exter_cause & External & Character \\
Sea_fact & Factors of sea & Character & Oth_enviro_fact & Other environment factor & Summary \\
Weat_fact & Factors of weather & Character & & & \\
\hline
\end{tabular}

Table 8. Human factors

\begin{tabular}{llllll}
\hline Name of field & Content & Type of data & Name of field & Content & Type of data \\
\hline Phys_fact & Mistake of physical factors & Character & Crew_viol & Crew violation & Character \\
Phyc_fact & Mistake of psychological factors & Character & Crew_unsf_act & Crew unsafe action & Character \\
Soc_med_fact & Mistake of social and medical factors & Character & Contri_acci & Latent conditions to contribute accident Character \\
Work_env_fact & Mistake of workplace and environment & Character & Oth_hum_fact & Other human factors & Summary \\
\hline
\end{tabular}

Table 9. Consequences of the incident

\begin{tabular}{lllll}
\hline Name of field & Content & Type of data & Name of field & Content \\
\hline Loca_date & Local date(yyyy/mm/dd) & Date & Dea_mis_pass & Dead or missing passengers \\
Loca_time & Local time(hh:mm) & Date & Dea_mis_oth & Dead or missing other person \\
Posit & Position(latitude ,longitude) & Character & Serinj_crew & Seriously injured crew \\
Locate & Location & Character & Serinj_pass & Seriously injured passengers \\
Ev_cont & Continuous event & Number & Serinj_oth & Seriously injured other persons \\
Ev_ord & Event order & Number & Tankoil_pol_type & Oil in tankers- pollution \\
Ev_type & Type of event & Character & Cargoil_pol_type & Oil cargo-pollution \\
Oth_ship_name & Other name of ship & Character & Chem_pol_type & Chemical in bulk-pollution \\
Pilot_onbo & Pilot on board & Logic & Dango_pol_type & Dangerous goods-pollution \\
Ship_end & Consequence of the ship & Character & Pol_quan & Quantity of pollution \\
Dea_mis_crew & Dead or missing crew & Number & Sum & Summary of events \\
\hline
\end{tabular}

\section{SYSTEM AND MODULE DESIGN}

\section{System structure}

The TMCDS provides personnel with the data required for maritime research and investigation. The HTML script is used in TMCDS to construct the basic web page for user interfaces, followed by inserting into ASP script code and SQL script to control database. The web-hierarchical structures of the system could be sim- plified as Figure 1. In TMCDS, three modules, namely, management module, operation module and storage module are designed. Each module is connected to the others by different levels of functions and authentications.

\section{Management module}

The management module is designed to guard the TMCDS system. For security purposes, this system is 
only accessible by authentic users. Through an application procedure, eligible users will be authorised to have a level of access right (Figure 2). Level one user could interrogate the general casualty database. Level two users are entitled to access to all casualty databases. Only level three users are qualified to register a new casualty or perform data modifications.

The process of new incident registration or data modification is shown in Figure 3. The process could be divided into four parts, including general information, causes, consequences, and functions of inquiry.

\section{Operation module}

The operation module consists of user interfaces and enquiry functions provided by the TMCDS. Users are categorised into general users, relation inquiry users and incident information providers etc. (Figure 4).

\section{Storage module}

The storage module comprises three different databases under main tables, attribute tables, and manage-

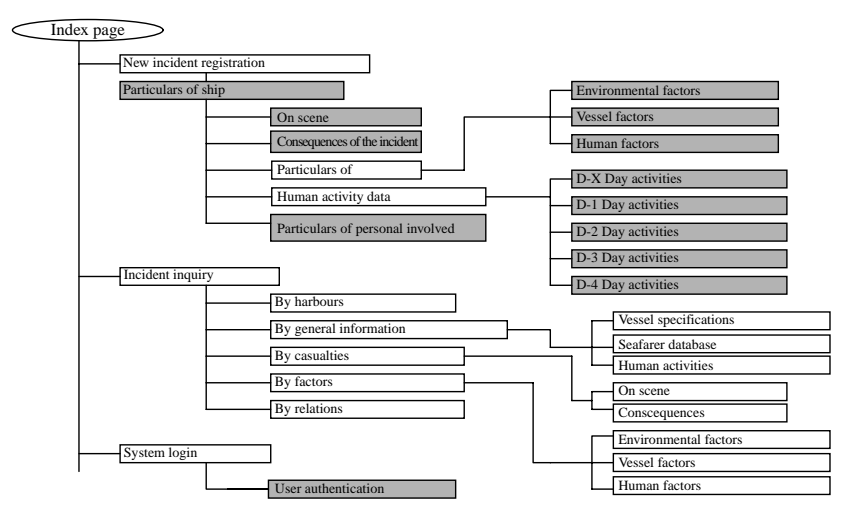

Fig. 1. Hierarchical structures of the TMCDS.

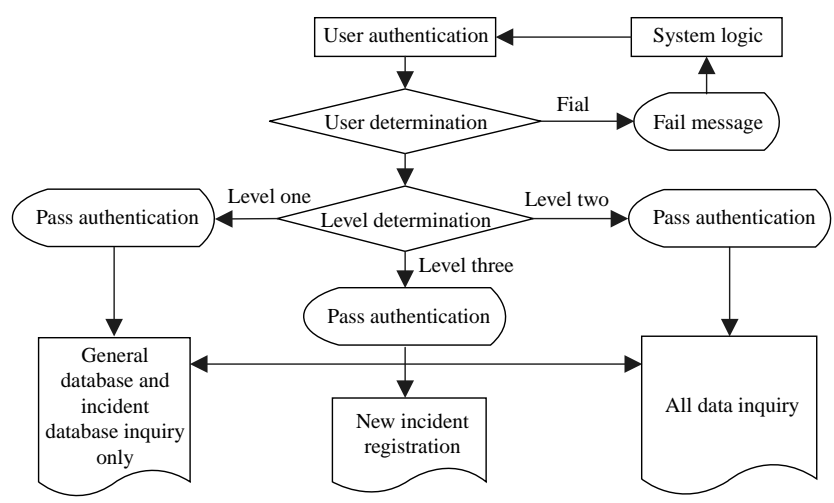

Fig. 2. Authentication process. ment tables. Information stored under the main tables include both categorised and classified static and dynamic data. Database stored under the attribute tables consists of all defined elements of different data such as type of ship, ship's hull, wind, weather conditions, type of event etc. Management tables consist of names, passwords and all personal information of the system users. Enquiry into the system can be done by following the different interfaces to access different tables (Figure 5).

\section{OPERATIONAL AND FUNCTIONAL TESTS}

\section{Database creation}

To register a new casualty case, a total of 460 fields of data are expected. These static and dynamic data include ship's particulars (69), information on seafarers (7), on-scene data (84), previous 96 hours activities (120), ship's factors (34), environmental factors (24), human factors (77), and consequences of the incident (45) etc. After a successful registration, a confirmation message will be replied to the user by the

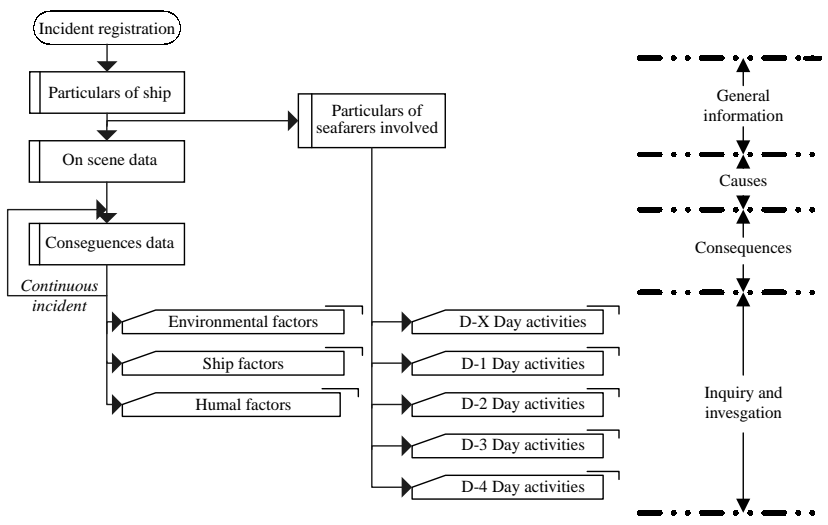

Fig. 3. Incident registration process.

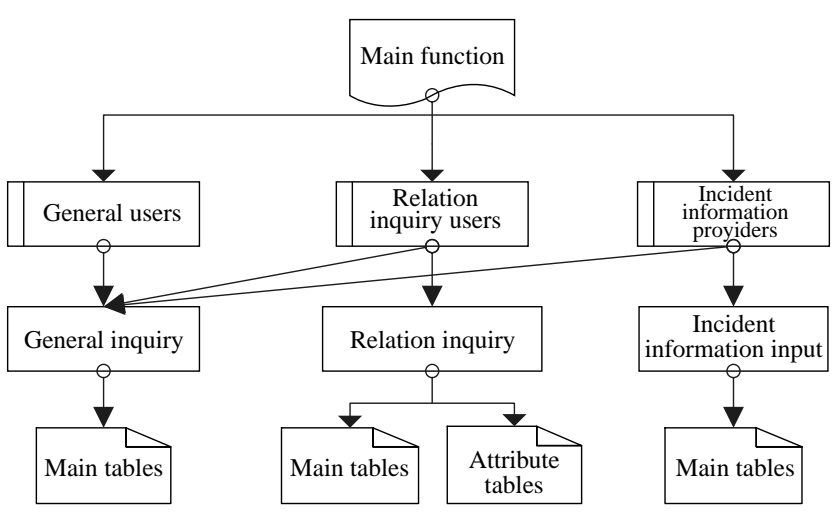

Fig. 4. Operation process. 
system with a code delegated to this casualty and the user is allowed to proceed with all the data registrations showing in Figures 6, 7, 8, and 9.

\section{Administrative enquiry}

Administrative enquiry is established in accordance with the regions of administrative responsibility of harbour bureaus and source of data provided by various harbour authorities and government agencies. Criteria of enquiry include ship's particulars, characters, and consequences of casualty. Related information are shown in Figures 10 and 11.

\section{Relation enquiry}

Relation enquiry is created to carry out an advanced search for users enquiring into the system by

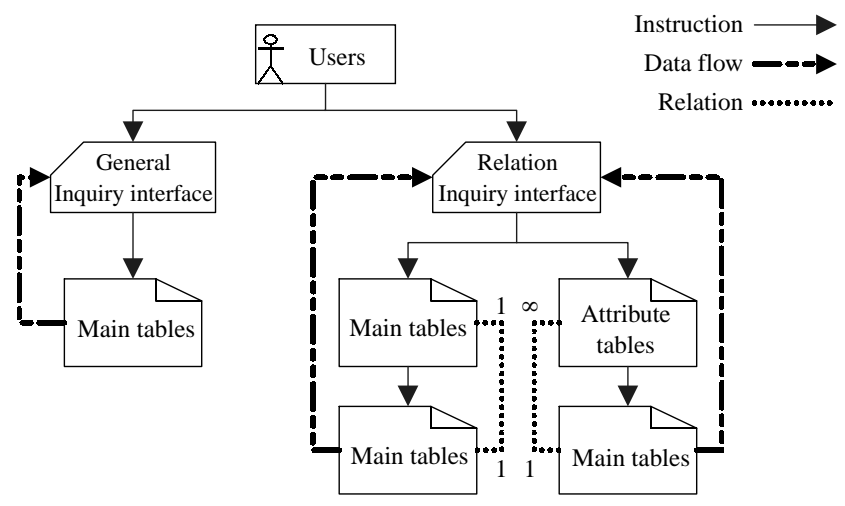

Fig. 5. System enquiry structure.

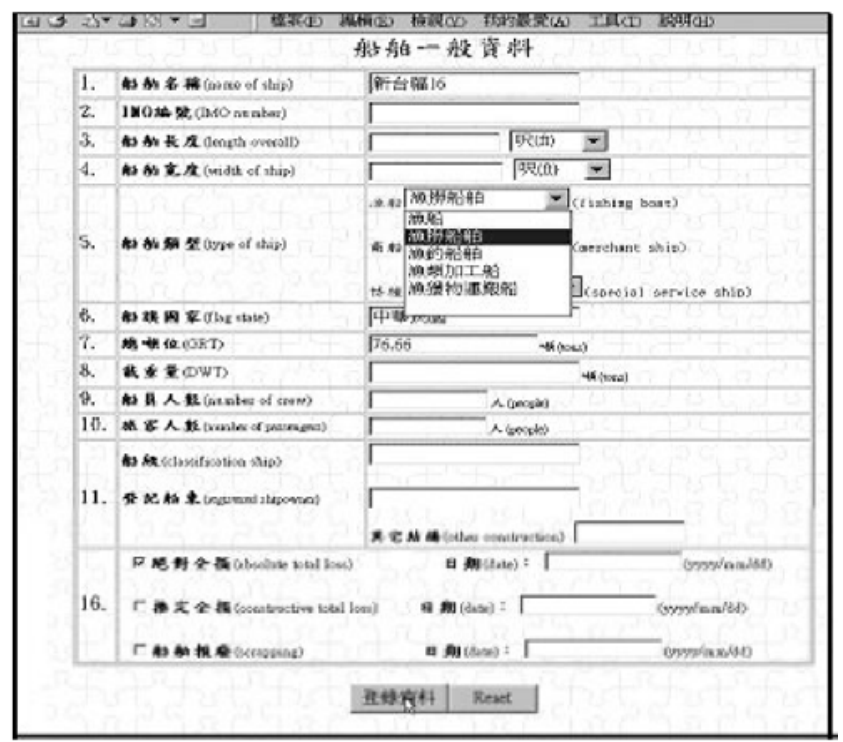

Fig. 6. Registration of ship's particulars. setting relational criteria that are more specific. Six types of relation enquiry are provided as follows (Figures 12 and 13):

(1) Ship, rank, and personnel activities.

(2) Types of ship, and consequences factors.

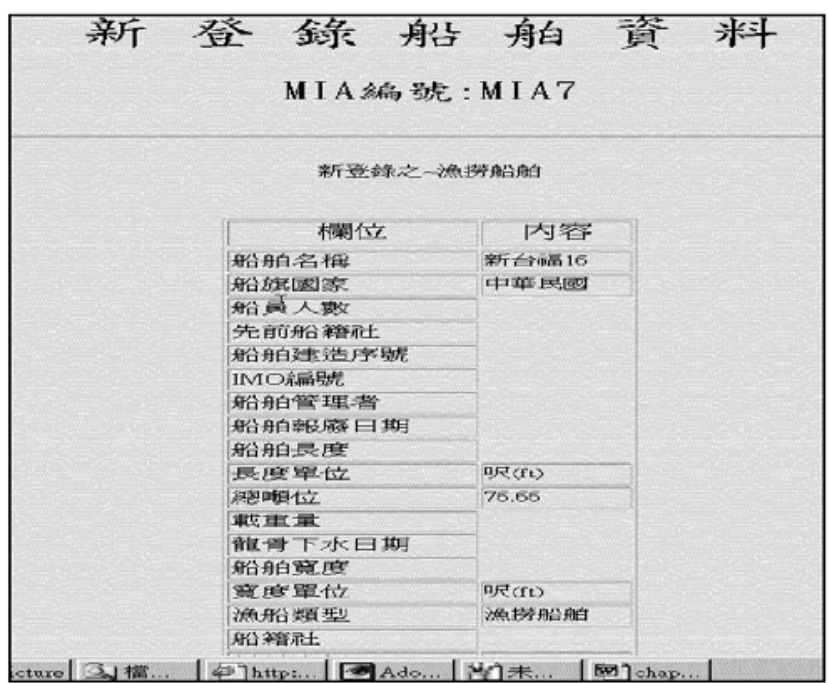

Fig. 7. Confirmation of registration of ship's particulars.

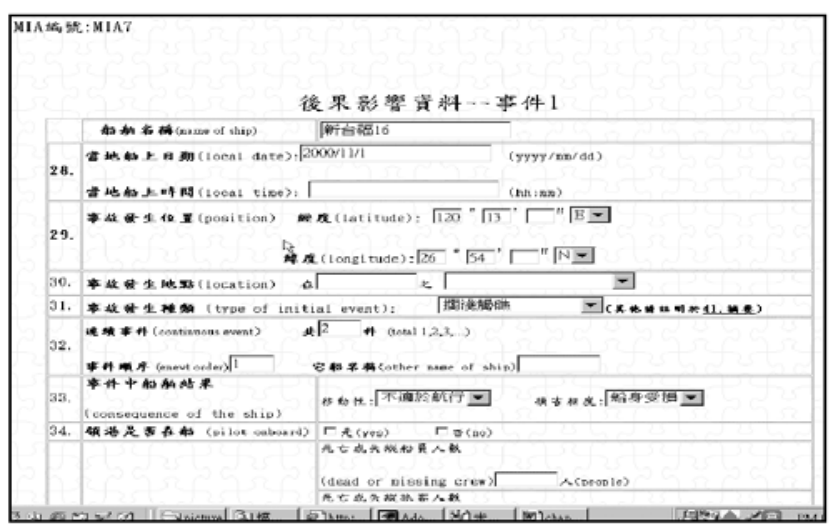

Fig. 8. Registration of consequences of the incident.

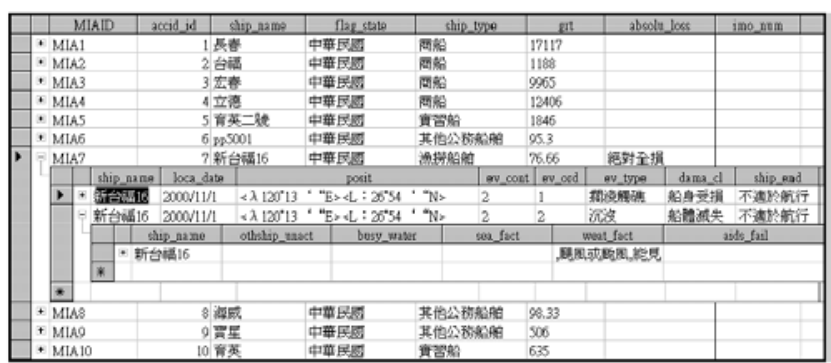

Fig. 9. Data from server side. 


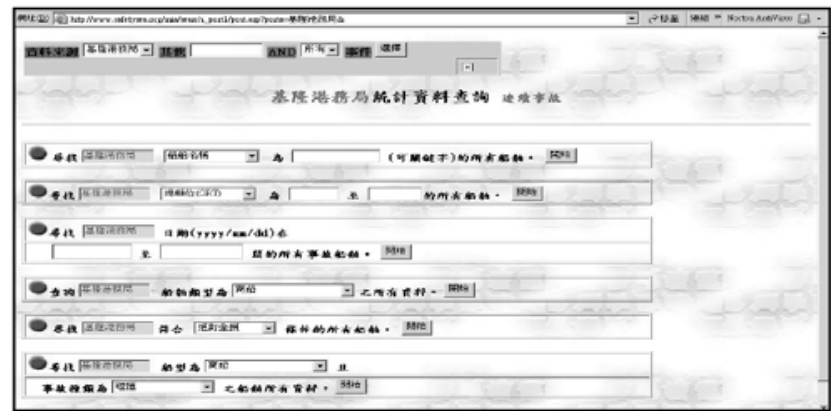

Fig. 10. Administrative enquiry by port authority and ship's particulars.

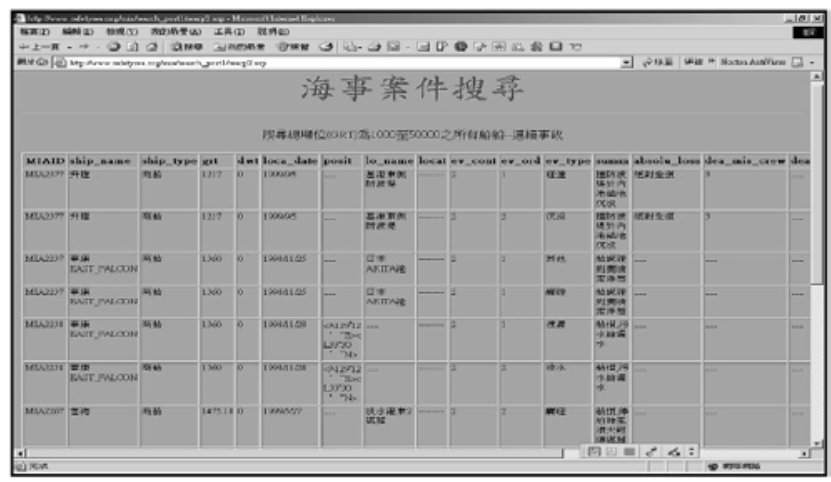

Fig. 11. Results of administrative enquiry.

(3) Types of ship, characters of casualty, and ship particulars.

(4) Characters of casualty and on-scene data.

(5) Location of casualty and on-scene dada.

(6) Pollution and on-scene data.

\section{CONCLUSION}

Shipping, fishery, and all the maritime activities are extremely important to Taiwan. Taiwanese economy had remarkable achievements in these fields in the last four decades. However, through an examination of Taiwan's maritime casualties' records, there is clear evidence showing that Taiwan's maritime achievements are building upon the sacrifice of life, loss of ships, pollution of the marine environment, and uncountable loss of properties.

Information technology in Taiwan had a high reputation worldwide. Taiwan has been the world's fourthlargest computer hardware supplier since 1995. The information technology industry is relatively strong, popular, acceptable and accessible to the public. However, the utilisation of IT as an administrative tool to supervise Taiwan's maritime safety affairs seems to

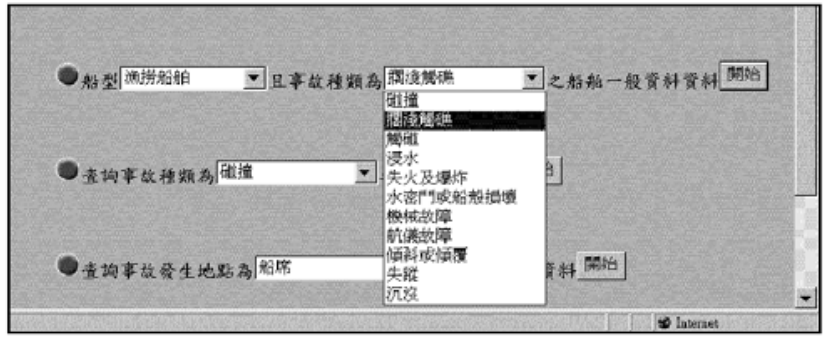

Fig. 12. Relation enquiry by types of ship, characters of casualty, and ship particulars.

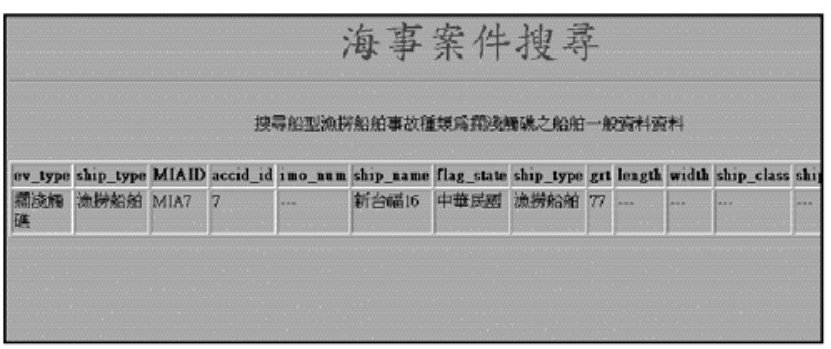

Fig. 13. Results of relation enquiry.

be sluggish or even stagnant. No doubt, maritime safety issues are alarming in Taiwan, and there is a strong need to diagnose Taiwan's maritime safety system. Data collected from maritime casualties is one of the most important links in the chain leading to effective measures to reduce the number of maritime casualties. Hence, the development of Taiwan's maritime casualty database system is essential and vital.

Although the prototype TMCDS system developed in the present study is constrained by limited research funding support, the operational functions, management functions, and storage functions have successfully embedded in the system. Moreover, a total of 2,927 casualty cases have also been recorded in the system by the authors. Now, the TMCDS became an important tool which attracts researchers and interested parties' enquiries.

Following the requirements set by international organizations and referring to different maritime casualty databases from many developed maritime countries, the function of the prototype TMCDS will be improved to a more convenient environment for search, retrieval, and management access to data in its database. The structure of the database will be expanded to include data, text, pictures, voice, and possibly video images. The integration with ECDIS or GIS is currently under study. In addition, it is also planned to add a data exchange program in TMCDS to receive casualty data from other countries for further maritime safety analysis. 
Last but not least, with an advantageous position of IT and economic strength, Taiwan has its wonderful environment for system development. However, the desirable and ideal TMCDS is still in the future. To receive Taiwan government's support and approval is one issue; to convert government's maritime casualty administrative duty from original paper works to a new computerized system and key-in details of all existed cases is another, even a challenge!

\section{REFERENCES}

1. Chen, Y.H., Establishment of Real-time Navigation Safety and Information Secure Systems for Cross-Strait Waters (1/2), Ministry of Transport and Communication, Taipei, Taiwan (2004). (in Chinese)

2. Chen, Y.H., The Prototype Design of Computerised Information Exchange Forms of Mission Command and Despatch for Coast Guard Administration, Coast Guard Administration, Taipei, Taiwan (2004). (in Chinese)

3. Chen, Y.H., Vision and Mission: Safety of Maritime Transport in Taiwan, Ship and Shipping Newsletter, (Report No. 5), Chinese Maritime Research Institute, Taipei, Taiwan, pp. 11-18 (2004). (in Chinese).

4. IMO, "Casualties," http://www.imo.org/Safety/ mainframe.asp?topic id=799, accessed 14 May 2004. 